\title{
Bcl-2 Family Gene Expression during Severe Hyperoxia Induced Lung Injury
}

\author{
Michael A. O’Reilly, Rhonda J. Staversky, Heidie L. Huyck, Richard H. Watkins, \\ Michael B. LoMonaco, Carl T. D’Angio, Raymond B. Baggs, William M. Maniscalco, \\ and Gloria S. Pryhuber
}

Departments of Pediatrics (Neonatology) (MAO, RJS, HLH, RHW, MBL, CTD, WMM, GSP) and of Pathology and Laboratory Medicine (RBB), School of Medicine and Dentistry, University of Rochester, Rochester, New York

SUMMARY: Exposure of the lung to severe hyperoxia induces terminal transferase dUTP end-labeling (TUNEL) indicative of DNA damage or apoptosis and increases expression of the tumor suppressor p53 and of members of the Bcl-2 gene family. Because cell survival and apoptosis are regulated, in part, by the relative abundance of proteins of the Bcl-2 family, we hypothesized that lung cells dying during exposure would show increased expression of pro-apoptotic members, such as Bax, whereas surviving cells would have increased expression of anti-apoptotic members, such as Bcl- $X_{L}$. The hypothesis is tested in the current study by determining which $\mathrm{Bcl}-2$ genes are regulated by hyperoxia, with specific focus on correlating expression of $\mathrm{Bax}$ and $\mathrm{Bcl}-\mathrm{X}_{\mathrm{L}}$ with morphologic evidence of apoptosis or necrosis. Adult mice exposed to greater than $95 \%$ oxygen concentrations for 48 to 88 hours had increased whole-lung mRNA levels of Bax and Bcl- $X_{L}$, no change in Bak, Bad, or Bcl-2, and decreased levels of Bcl-w and Bfl-1. In situ hybridization revealed that hyperoxia induced Bax and Bcl- $X_{L}$ mRNA in uniform and overlapping patterns of expression throughout terminal bronchioles and parenchyma, coinciding with TUNEL staining. Electron microscopy and DNA electrophoresis, however, suggested relatively little classical apoptosis. Unexpectedly, Western analysis demonstrated increased $\mathrm{Bcl}-\mathrm{X}_{\mathrm{L}}$, but not Bax, protein in response to hyperoxia. Bax and Bfl-1 were not altered by hyperoxia in $p 53$ null mice; however, oxygen toxicity was not lessened by $p 53$ deficiency. These findings suggest that oxygen-induced lung injury does not depend on the relative expression of these Bcl-2 members. (Lab Invest 2000, 80:18451854).

$H$ igh concentrations of oxygen, required for treatment of human pulmonary and cardiovascular disease, injure and kill pulmonary cells. After nearly 30 years of research, however, it is not clear how oxygeninduced lung cell death occurs. Detailed morphologic observations in rodents revealed that exposure to greater than $85 \%$ oxygen concentrations for 48 hours caused cytoplasmic swelling of microvascular endothelial cells followed by cellular fragmentation (Adamson et al, 1970; Crapo et al, 1980; Crapo, 1986). The alveolar epithelium was affected after 72 hours of exposure when swelling of alveolar type I cells was observed. Hyaline membranes, edema, and mortality occurred shortly thereafter in association with the disruption of type I cells. The majority of the dying cells had swollen mitochondria and endoplasmic reticulum, pyknotic nuclei with swelling of the perinuclear cister-

Received July 20, 2000.

This work was supported in part by grants from the American Heart Association Beginning grant-in aid (9860004T), NIEHSC pilot project (ES01247), and HL58774 (MAO). HL36543 (WMM), KO8 HL03493 (CTD), and KO8 HL03318-5 (GSP) provided additional support. The animal exposures were performed using core facilities supplied through the Environmental Health Sciences Center at Rochester (ESO1247).

Address reprint requests to: Dr. Michael A. O'Reilly, Department of Pediatrics (Neonatology), Box 777, Children's Hospital at Strong, The University of Rochester, 601 Elmwood Avenue, Rochester, NY 14642. Fax: 716756 7780; E-mail: michael_oreilly@urmc.rochester.edu nae, rupture of plasma membranes, and loss of adherence to the basement membrane. These morphologic observations are consistent with cellular necrosis resulting from homeostatic failure (Raffray and Cohen, 1997).

Although the morphologic data suggest that pulmonary cells die by necrosis in hyperoxia, recent studies suggest that apoptotic programmed cell death is also induced in lungs exposed to high levels of oxygen. Apoptosis is a regulated process by which cellular organelles shrink and divide into small membranebound remnants that are phagocytosed by adjacent cells (Kerr et al, 1972). Various initiators of apoptosis have been discovered. These initiators converge on a common pathway in which a family of cysteine proteases (caspases) are activated by proteolysis (Thornberry and Lazebnik, 1998). Activated caspases result in events characteristic of apoptosis, including fragmentation of DNA into nucleosomal repeats (Enari et al, 1998; Liu et al, 1998). Such DNA fragmentation can be detected by terminal transferase dUTP endlabeling (TUNEL) and by electrophoretic size fractionation of cellular DNA (DNA laddering). We and others have observed increased TUNEL staining in bronchiolar and alveolar cells of mouse lungs exposed to lethal hyperoxia, suggesting oxygen-induced apoptotic cell death (Barazzone et al, 1998; O'Reilly et al, 1998a; Waxman et al, 1998). The specificity of TUNEL staining in identifying apoptotic cells in oxygen-exposed 
lung tissue has recently been questioned, in part, because cells appearing resistant to hyperoxia by morphology, such as terminal bronchiolar and alveolar type II epithelial cells, are notably TUNEL-positive. The finding that surfactant protein $B$ and transforming growth factor- $\beta$ expression are increased in hyperoxia-exposed terminal bronchiolar epithelial cells also contradicts the concept that these TUNELpositive cells are undergoing apoptosis (O'Reilly et al, 1997; Wikenheiser et al, 1992). Hyperoxia-induced nucleosomal cleavage of DNA, consistent with apoptosis and detected by DNA laddering assays, has also been difficult to detect even though up to $50 \%$ of alveolar cells appear TUNEL-positive (O'Reilly et al, 2000; Waxman et al, 1998). It is therefore unclear whether hyperoxia-induced TUNEL staining signifies classical apoptosis or another form of DNA damage or fragmentation.

Another method to determine if apoptosis is a significant response to hyperoxia is to assess expression of pro- and anti-apoptotic genes involved in cell survival and death. The Bcl-2 family of proteins plays a predominant role in the induction and prevention of apoptosis (Adams and Cory, 1998). Bcl-2 was originally cloned as a gene activated by translocation in follicular lymphoma cells that permitted survival of hematopoietic cells deprived of IL-3 (Tsujimoto et al, 1984). At least 15 homologous Bcl-2 family members, which possess at least one of four conserved $\mathrm{Bcl}-2$ homology domains ( $\mathrm{BH} 1$ to $\mathrm{BH} 4)$, have now been identified as either promoting or inhibiting apoptosis (Adams and Cory, 1998). Most members of the antiapoptotic subfamily, such as $\mathrm{Bcl}-\mathrm{X}_{\mathrm{L}}$ and $\mathrm{Bcl}-\mathrm{w}$, contain $\mathrm{BH} 1$ through $\mathrm{BH} 4 \mathrm{Bcl}-2$ homology domains. In contrast, pro-apoptotic subfamilies are identified by homology to Bax and the $\mathrm{BH} 3$ domain. Bcl-2 proteins form homo- and heterodimers with one another, such that relative differences in their abundance can have dramatic effects on whether cells live or die. For example, elevated levels of Bax promote apoptosis by disrupting Bcl-2 dimers (Oltvai et al, 1993; Yin et al, 1994). It is important, therefore, to determine relative changes in expression of $\mathrm{Bcl}-2$ members in lung exposed to hyperoxia because pulmonary cell survival may depend on the relative abundance of these proteins. Recent studies have shown that hyperoxia increased mRNA levels of Bax and $B c l-X_{L}$ (Barazzone et al, 1998). The cellular localization of Bax and Bcl- $X_{L}$ expression in the lung has not been determined. Furthermore, it is not known whether Bax and Bcl- $\mathrm{X}_{\mathrm{L}}$ proteins are also increased by oxygen exposure or whether expression of other $\mathrm{Bcl}-2$ genes is altered by hyperoxia. Thus, assessing cellular localization and abundance of these genes can provide insight into their importance during hyperoxic lung injury.

An alternative approach to ascertaining the importance of these genes is to clarify and manipulate molecular signals that regulate the expression of specific members of the Bcl-2 family. The tumorsuppressor protein p53 increases in cells with DNA damage and promotes apoptosis, in part, by increasing Bax transcription. Several studies have shown that hyperoxia increases p53 in terminal bronchioles and alveolar type II cells of mice (Barazzone et al, 1998; O'Reilly et al, 1998a). Although p53-deficiency does not modify lung injury as assessed by wet to dry lung ratios or TUNEL assay, it has not been determined whether p53-deficiency altered expression of Bcl-2 members (Barazzone et al, 1998; O’Reilly et al, 2000). Using adult mice exposed to lethal levels of oxygen, we now show that hyperoxia has varied effects on expression of different members of the Bcl-2 family and that changes in Bax and Bfl-1 expression are dependent upon p53. Since p53-deficiency does not modify lung injury, our findings suggest that relative change in the expression of these members of the Bcl-2 family are not primarily responsible for oxygeninduced lung injury.

\section{Results}

\section{Hyperoxic Lung Injury Defined by Electron Microscopy in Comparison with TUNEL Assay}

Morphologic changes resulting from hyperoxia were detected by electron microscopy and compared with the occurrence of hyperoxia-induced TUNEL staining. An occasional faint TUNEL-positive cell was observed in lungs of $\mathrm{C} 57 \mathrm{BI} / 6 \mathrm{~J}$ wild-type mice exposed to room air (Fig. 1A). In contrast, over $50 \%$ of the nuclei in the parenchyma of mice exposed to hyperoxia for 48 hours were TUNEL-positive (Fig. 1B). Lungs exposed to hyperoxia for 84 hours had intense TUNEL staining in the majority of cells of the alveolar septum as well as in intra-alveolar debris, the latter consistent with release of DNA from dead cells (Fig. 1C). While the majority of cells were TUNEL-positive, TUNELnegative cells were also found. TUNEL staining was not detected in cytoplasm of intact cells or in sections reacted in the absence of terminal transferase (data not shown, and O'Reilly et al, 1998a), demonstrating the specificity of the stain for DNA.

TUNEL staining identifies cells with fragmented DNA, indicative of apoptosis, necrosis, and/or simple DNA strand breaks (Ansari et al, 1993; Grasl-Kraupp et al, 1995). Electron microscopy was used to determine the ultrastructure of parenchymal cells where TUNEL staining was observed. Lungs exposed to room air contained intact alveolar septae (Fig. 1D). The nuclei of most cells contained randomly distributed heterochromatin. Microvilli were observed on type I and II epithelial cells. Similar morphology was observed in lungs exposed to hyperoxia for 48 hours (Fig. 1E). Margination of chromatin, condensation, and fragmentation of nuclei were not readily apparent, even though abundant TUNEL-positive cells were observed. In contrast, morphologic signs of cell injury and death were observed in lungs exposed to hyperoxia for 84 hours (Fig. 1F). Pronounced interstitial swelling was evident along with necrotic cell debris that was most likely from fragmentation of type I cells. Loss of microvilli was the most prominent feature of injury to type II cells. Morphologic signs of apoptosis were not obvious. In summary, despite high frequency 

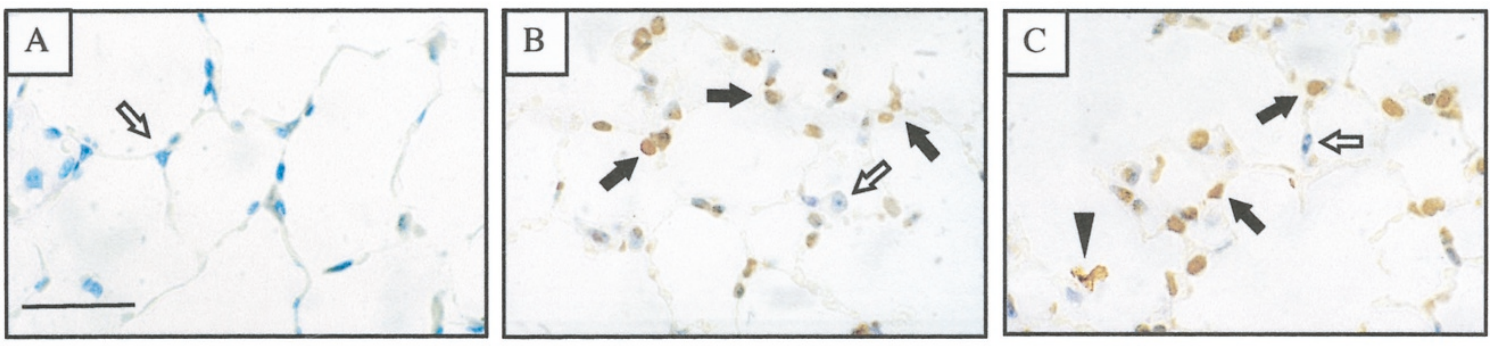

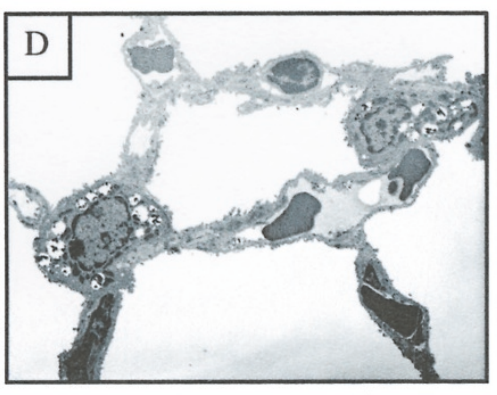

Room Air

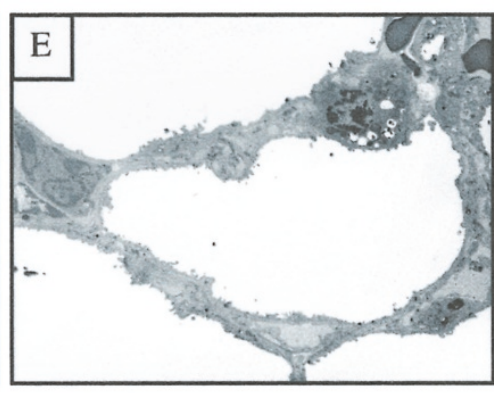

Hyperoxia (48 hours)

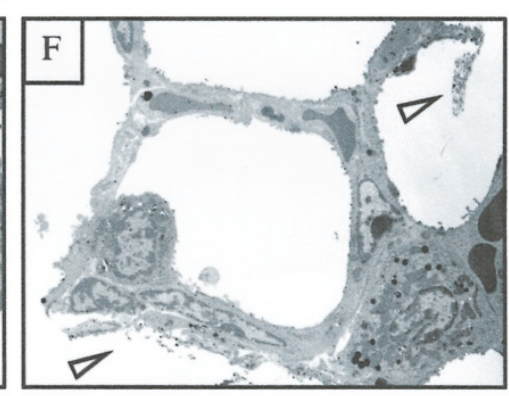

Hyperoxia ( 84 hours)

Figure 1.

Hyperoxia induces DNA fragmentation. Adult mice were exposed to room air $(A, D)$ or hyperoxia for $48(B, E)$ or $84(C, F)$ hours. Sections of lung were stained for the presence of free $3^{\prime}$-hydroxyl ends on DNA using terminal transferase and digoxigenin-conjugated nucleotides, visualized as a dark brown stain ( $A$ to $C$ ). Filled arrow, TUNEL positive cell; filled arrowhead, TUNEL positive debris; open arrow, TUNEL negative cell. Sections were counterstained with methyl green. Bar in $A=$ $40 \mu \mathrm{m}$. Ultrastructural analysis by electron microscopy revealed intact chromatin at all times studied, with cell debris (open arrowhead) observed by 84 hours of hyperoxia. $D$ to $F$, Magnification, $\times 2000$.

of TUNEL-positive cells, very few of the parenchymal cells demonstrated morphology consistent with classical apoptotic cell death. In addition, DNA isolated from lungs exposed to 72 hours of oxygen did not, in comparison with lungs exposed to room air, demonstrate consistent increase in laddering, expected for apoptotic cells, again suggesting that the TUNEL stain overestimates the proportion of apoptotic cells in oxygen-injured lung tissue (Fig. 2). Note that the gels were stained with SYBR Green I because no DNA laddering was detected when ethidium bromide was

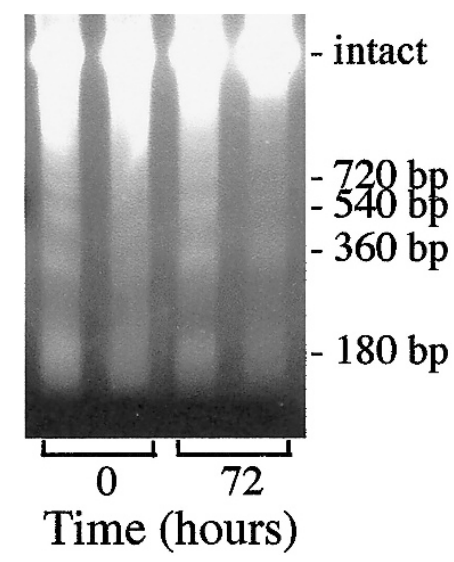

Figure 2.

DNA Ladder. Representative agarose gel demonstrating genomic DNA isolated from lungs exposed to room air ( $0 \mathrm{hr}$ ) or hyperoxia for 72 hours, separated by electrophoresis and visualized with SYBR Green I. Variable amounts of regular sized, small-molecular-weight DNA were observed in both room air and hyperoxia-exposed samples. used to label the DNA. The observed low level of laddered DNA is consistent with results of other studies that selectively purified and radiolabeled small molecular weight DNA to demonstrate DNA laddering (Barazzone et al, 1998; Waxman et al, 1998).

\section{Hyperoxia Alters mRNA Expression of Bcl-2 Family Members}

To further characterize the presence of apoptosis in oxygen-exposed lung, changes in expression of several Bcl-2 genes were assessed. Total RNA was isolated from lungs and hybridized to a pool of $\left[{ }^{32} \mathrm{P}\right]-$ labeled antisense RNA probes corresponding to Bcl-w, Bfl-1 (also designated A1), Bcl-X $\mathrm{L}_{\mathrm{S}}$, Bak, Bax, $\mathrm{Bcl}-2$, Bad, L32, and GAPDH. Protected products were purified following RNase digestion, resolved by denaturing electrophoresis, and quantified by Phosphorlmage analysis. Messenger RNA levels for each of these genes were detected in lung samples prepared from room air- and oxygen-exposed mice. As summarized in Figure 3, the effect of hyperoxia on $\mathrm{Bcl}-2$ family member mRNAs in whole lung samples was highly member-dependent. Of the genes studied that promote apoptosis, hyperoxia increased the expression of Bax mRNA and had no effect on the expression of Bad or Bak. Messenger RNA for $\mathrm{Bcl}-\mathrm{X}_{\mathrm{S}}$ was not detected. In contrast, of the genes studied that inhibit apoptosis, hyperoxia increased the expression of $\mathrm{Bcl}-\mathrm{X}_{\mathrm{L}} \mathrm{mRNA}$, decreased the expression of $\mathrm{Bcl}-\mathrm{W}$ and $\mathrm{Bfl}-1$, and had no effect on the expression of Bcl-2.

Because the Bax and Bcl- $X_{L}$ genes demonstrated the greatest positive response to hyperoxia, we chose 


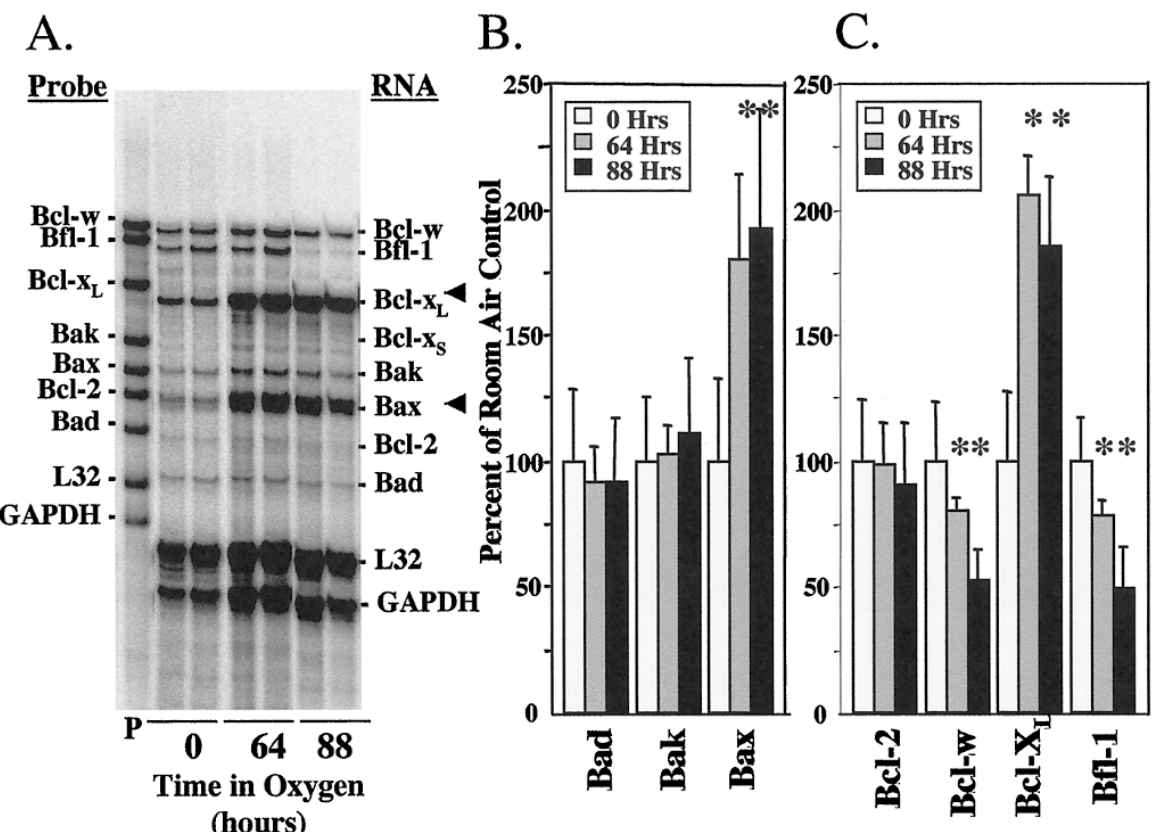

Figure 3.

Hyperoxia alters the expression of Bcl-2 family members. Total lung RNA (5 $\mu \mathrm{g}$ ), isolated from mice exposed to hyperoxia (> $95 \%$ ) for 0, 64, or 88 hours (white, gray, and black bars, respectively), was annealed to [ $\left.{ }^{32} \mathrm{P}\right]$ labeled antisense riboprobes (Probe - undigested probe, provides size marker), digested with RNase and separated by electrophoresis. $A$, Representative ribonuclease protection assay (RPA). Expected positions of protected products for each mRNA are indicated. Arrows depict the marked induction observed in Bcl- $X_{L}$ and Bax mRNAs. $B$ and $C$, Cumulative data. Pro-apoptotic $(B)$ and anti-apoptotic $(C)$ Bcl-2 family mRNAs were quantified by phosphorimaging of RPAs, normalized to L32 mRNA content and expressed relative to room air exposed controls. Bars indicate mean \pm standard deviation, $n=4-5$ mice/group; * indicates $p<0.001$ versus room air control; data representative of more than three experiments.

to study their pattern of expression in greater detail. First, Northern blot analysis was used to authenticate the protected products observed by RNase protection. Room air-exposed lungs had low levels of Bax and $\mathrm{Bcl}-\mathrm{X}_{\mathrm{L}}$ mRNAs (Fig. 4). The abundance of both genes increased modestly after 48 hours (data not shown), increased further by 64 hours, and remained elevated after 88 hours of exposure to greater than 95\% oxygen. Quantitative analysis following normalization to $\mathrm{L} 32$ expression revealed $\mathrm{Bcl}-\mathrm{X}_{\mathrm{L}}$ expression increased $5.1 \pm 0.5$-fold $(p<0.001)$ (Fig. 4B) and Bax expression increased $3.6 \pm 0.2$-fold $(p<0.001)$ (Fig. $4 \mathrm{C})$ after 88 hours of exposure to hyperoxia.

\section{Localization of Bax and BcI- $X_{L}$ mRNAs}

To localize the expression of $B a x$ and $B c l-X_{L}$ mRNA induction, in situ hybridization was performed with riboprobes generated from the cDNA used for Northern blot analysis. Room air-exposed lungs had low levels of Bax expressed uniformly throughout the lung, consistent with the low signal obtained by RNase protection assay and Northern analysis (Fig. 5A). After exposure to hyperoxia, Bax expression increased in the bronchiolar epithelium and in cells of the alveolar septal walls (Fig. 5B). Similarly, low levels of Bcl- $X_{L}$ mRNA were detected throughout the lungs of mice exposed to room air (Fig. 5D). Hyperoxia increased $\mathrm{Bcl}-\mathrm{X}_{\mathrm{L}}$ expression throughout the bronchioles and parenchyma in a pattern similar to that of Bax (Fig. 5E). Closer examination revealed that $\mathrm{Bax}$ and $\mathrm{Bcl}-\mathrm{X}_{\mathrm{L}}$ mRNAs were expressed uniformly throughout the pa- renchyma, including the endothelial cells of small blood vessels. In contrast, $\mathrm{Bax}$ and $\mathrm{Bcl}-\mathrm{X}_{\mathrm{L}}$ were not readily detected in smooth muscle underlying arteries of lungs exposed to room air or hyperoxia (open star, Fig. 5, B and E). Sections hybridized with sense probes displayed a background with fewer grains than the room air-exposed lungs (Fig. 5, C and F).

\section{Hyperoxia Increases $B c 1-X_{L}$ but Not Bax Protein}

Western blot analysis was utilized in order to determine whether increased $\mathrm{Bax}$ and $\mathrm{Bcl}-\mathrm{X}_{\mathrm{L}}$ mRNA was reflected in increased protein content (Fig. 6). Hyperoxia increased $\mathrm{Bcl}-\mathrm{X}_{\mathrm{L}}$ protein $3.1 \pm 0.55$-fold $(p<$ 0.005). In contrast, no increase in Bax protein was observed. Attempts to semiquantify these proteins at the cellular level by immunohistochemistry have been unsuccessful with currently available antibodies.

\section{Bax Induction Is Dependent upon p53}

Previous studies have shown increased expression of the transcription factor p53 in mouse lungs exposed to hyperoxia (Barazzone et al, 1998; O'Reilly et al, 1998a). In other models of cell injury, p53 promotes apoptosis by increasing Bax transcription (Friedlander et al, 1996). p53 wild-type $(+/+)$ and null (-/-) mice were exposed to hyperoxia for 84 hours to determine whether changes in $\mathrm{Bcl}-2$ family members were dependent upon p53. Gene expression was determined by RNase protection analysis and normalized to the expression of L32. Hyperoxia increased Bax mRNA in 
A.

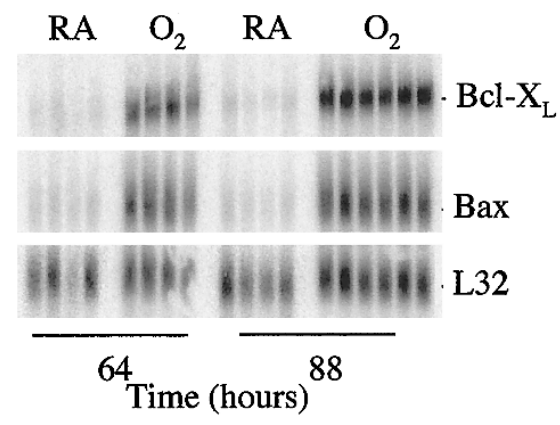

B.

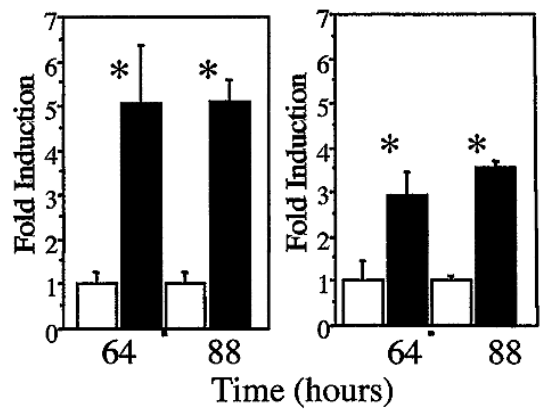

Figure 4.

Northern analysis of hyperoxia induced $\mathrm{Bax}$ and $\mathrm{Bcl}-\mathrm{X}_{\mathrm{L}}$ mRNA expression. $A$, Total lung RNA $(20 \mu \mathrm{g})$ isolated from mice exposed to room air (RA) or hyperoxia $\left(\mathrm{O}_{2}\right)$ for 64 or 88 hours was electrophoresed, transferred to membrane, and hybridized with [ $\left.{ }^{32} \mathrm{P}\right]$-labeled cDNAs for Bax, Bcl- $\mathrm{X}_{\mathrm{L}}$, and L32. $B$ and $C$, The hybridization intensity was quantified by phosphorimaging, normalized to the expression of $\mathrm{L} 32$ and graphed relative to the values of RA-exposed mice (means $\pm \mathrm{SD}$ ). $\mathrm{Bcl}-\mathrm{X}_{\mathrm{L}}(B)$ and $\mathrm{Bax}(C)$ were increased at 64 and 88 hours of exposure to hyperoxia. ${ }^{*} p<0.001$ vs RA.

p53-wild-type, but not in p53-deficient, lungs (Fig. 7A). In contrast, hyperoxia increased Bcl- $X_{L}$ (Fig. 7B) and reduced $\mathrm{Bcl}-\mathrm{w}$ (data not shown) mRNA independent of p53. Bfl-1 mRNA, which was inhibited by hyperoxia in wild-type mice, demonstrated no change in expression in p53 null mice (Fig. 7C). As shown for Bcl-2 (Fig. 7D), hyperoxia did not alter the expression of the remaining family members tested, either in the presence or absence of p53. These findings reveal that p53 participates in some, but not all, of the oxygen-induced changes in expression of $\mathrm{Bcl}-2$ members.

\section{p53-Deficiency Does Not Modify Hyperoxic Lung Injury}

Because changes in Bax and Bfl-1 are dependent upon p53, we hypothesized that if these genes contribute to oxygen-induced lung injury, then p53deficient mice should be more resistant to hyperoxia. In fact, previous studies of edema and TUNEL staining in $p 53$ null versus wild-type mice, suggest that $p 53-$ deficient mice are not resistant to severe hyperoxia (Barazzone et al, 1998; O’Reilly et al, 2000). Sections prepared from the lungs of $p 53(+/+)$ and (-/-) mice exposed to room air or hyperoxia for 84 hours were analyzed histologically for inflammation, edema, cell death, and DNA fragmentation. Lungs of p53 $(+/+)$ and (-/-) mice exposed to room air were normal and indistinguishable from one another (data not shown). In contrast, lungs of either strain exposed to hyperoxia had markedly increased necrosis and edema in the terminal bronchioles associated with swelling of underlying basement membrane and increased recruitment of inflammatory cells, including neutrophils and macrophages. Similarly, abundant TUNEL-positive staining was observed in cells and intra-alveolar debris of both strains consistent with cell necrosis (Fig. 8). The marked increase in cell debris observed in this figure compared with Figure 1 may be due to strain differences, which have been shown to temporally modify lung injury (Johnston et al, 1998). Although tissue injury appeared equivalent in p53 (+/+) and (-/-) lungs, there was a tendency for $p 53$ (-/-) lungs to have more edema and necrosis of the terminal bronchioles than $p 53(+/+)$ lungs (data not shown).

\section{Discussion}

Exposure of mammalian lungs to lethal levels of oxygen results in the death of endothelial and epithelial cells, leading to edema, respiratory distress, and mortality. Previous studies have shown that lungs injured by hyperoxia show morphologic signs of necrosis, as well as positive TUNEL staining, indicative of DNA fragmentation and/or apoptosis (Adamson et al, 1970; Crapo et al, 1980; Crapo, 1986; Kazzaz et al, 1996; O'Reilly et al, 1998a; Waxman et al, 1998). The present study extends these observations by demonstrating that lethal levels of oxygen alter the expression of members of the Bcl-2 gene family, genes that, in many models, determine cell survival or death (Cory, 1998). The hypothesis was that lung cells sensitive to oxygen-induced apoptotic cell death (ACD) would express a predominance of pro-apoptotic $\mathrm{Bcl}-2$ gene family members, whereas cells resistant to ACD would express relatively more anti-apoptotic $\mathrm{Bcl}-2$ genes. The observations are that mRNA levels of both proand anti-apoptotic Bcl-2 family members were altered by hyperoxia in such a pattern as to suggest that cell death is not simply associated with change in the ratio of pro-apoptotic to anti-apoptotic Bcl-2 gene expression. For example, hyperoxia increased expression of the pro-apoptotic Bax and anti-apoptotic Bcl- $X_{L}$ in an overlapping pattern in the bronchioles and parenchyma, and not in a cell-exclusive manner. Posttranscriptional control was also evident in that, although $\mathrm{Bcl}-\mathrm{X}_{\mathrm{L}}$ protein was induced by hyperoxia in parallel with increased mRNA, Bax protein was not increased despite increased Bax mRNA. In addition, hyperoxia induced similar degrees of DNA fragmentation and lung injury in $p 53$ wild-type and null mice even though Bax or Bfl-1 expression was not altered in the p53-deficient mice. Thus, failure to alter Bax or Bfl-1 expression does not significantly modify injury of lungs exposed to severe levels of hyperoxia.

Hyperoxia injures and kills alveolar endothelial cells and type I epithelial cells (Adamson et al, 1970; Crapo et al, 1980). If the death of parenchymal cells were occurring by apoptosis regulated by $\mathrm{Bcl}-2$ proteins, 

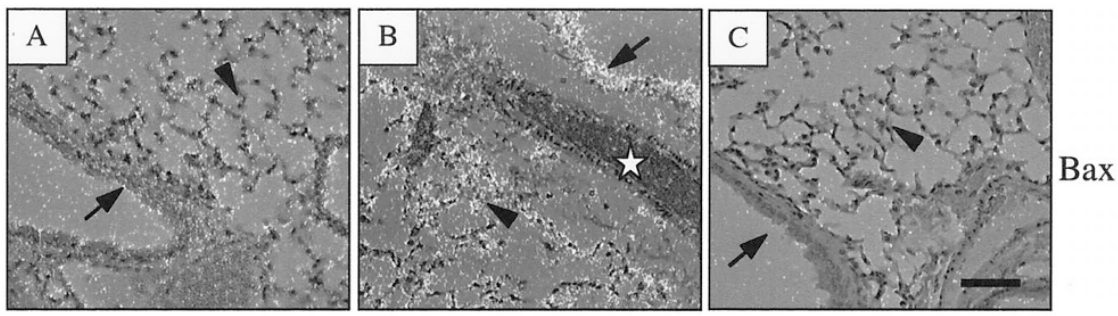

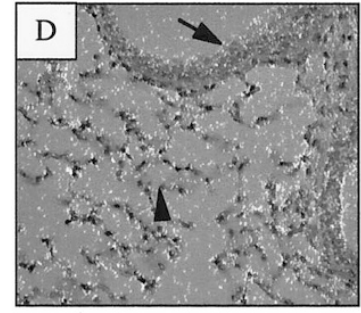

Room Air

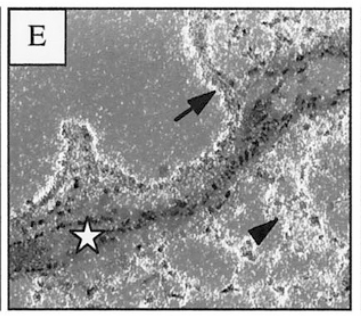

Hyperoxia

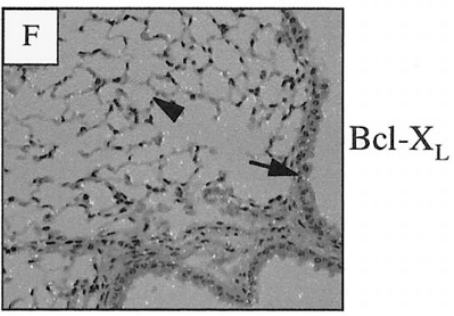

Room Air

(Sense Probe)

Figure 5.

Localization of Bax and Bcl- $X_{L}$ mRNAs. Mice were exposed to room air $(A, C, D, F)$ or hyperoxia for 93 hours $(B, E)$. Sections of lung were hybridized with $\left[{ }^{33} P\right]$-labeled antisense $\operatorname{Bax}(A, B)$ or $B c l-X_{L}(D, E)$ probes. Signal specificity for each probe was confirmed by hybridizing with $\left[{ }^{33} \mathrm{P}\right]$-labeled sense $\mathrm{Bax}(C)$ or $\mathrm{Bcl}-\mathrm{X}_{\mathrm{L}}(F)$ probes. Sections were counterstained with hematoxylin and eosin. Arrow depicts airway, arrowhead depicts parenchyma, and open star depicts large blood vessel. Bar in $C$ $=100 \mu \mathrm{m}$.

A.

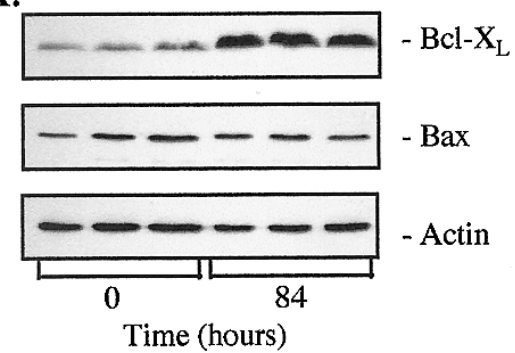

B.

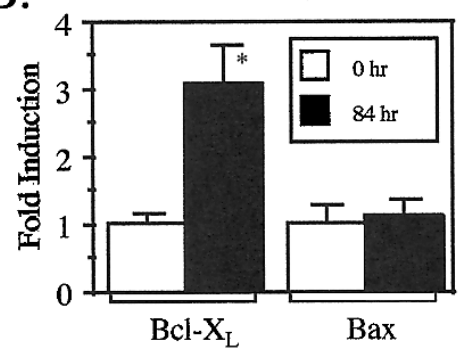

Figure 6.

$\mathrm{Bcl}-\mathrm{X}_{\mathrm{L}}$, but not Bax, protein is induced by hyperoxia. Mouse lung was homogenized in lysis buffer following exposure to room air (0 hr) or $>95 \%$ oxygen for 84 hours. Western analysis of total protein $(50 \mu \mathrm{g})$ for $\mathrm{Bcl}-\mathrm{X}_{\mathrm{L}}, \mathrm{Bax}$, and actin as a loading control was performed as described in the "Materials and Methods" section. A, Representative Western analysis. B, Quantification of proteins by densitometry of Western radiographs, normalized to actin levels. Bars $=$ mean $\pm \mathrm{SD} ; n=3 ;{ }^{*}$ denotes $p<0.005$ vs RA.

one would expect that these cells would have relatively increased expression of pro-apoptotic or decreased expression of anti-apoptotic members. Our study analyzed a subset of Bcl-2 family members that included each of the known anti-apoptotic, BH1-4 domain-containing $\mathrm{Bcl}-2$ genes, except $\mathrm{Mcl}-1$, and each of the $\mathrm{BH} 1-3$ domain-containing pro-apoptotic
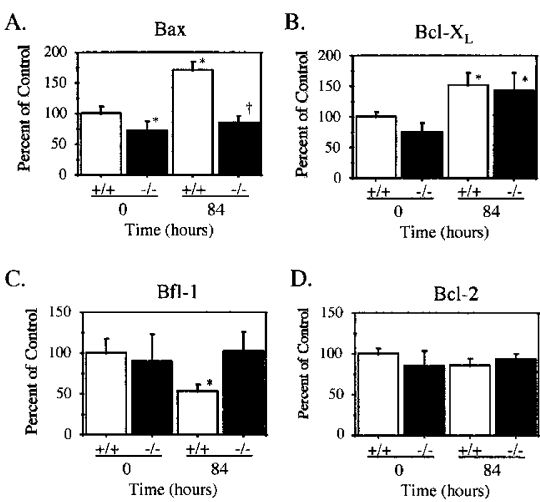

\section{Figure 7.}

Regulation of Bax, Bcl- $\mathrm{X}_{\mathrm{L}}, \mathrm{Bfl}-1$, and Bcl-2 in p53-deficient mice. $p 53(+/+)$ (open bar) and $p 53(-/-)$ (filled bar) mice were exposed to room air or hyperoxia for 84 hours. Total lung RNA $(5 \mu \mathrm{g})$ was analyzed by RPA. The intensities of the protected fragments were normalized to the expression of $\mathrm{L} 32$ and graphed relative to the expression of the wild-type mice (mean $\pm \mathrm{sD}$; $n=3$ ). $A$, Bax expression was significantly lower in room air exposed $p 53$-null lungs versus $p 53(+/+)$ lungs and was increased by hyperoxia only in the presence of $p 53\left({ }^{*} p<0.05\right) . B, B c l-X_{L}$ gene regulation was not significantly affected by p53-deficiency. $C$, Bfl-1 was decreased by hyperoxia only in $p 53$ $(+/+)$ mice $\left({ }^{*} p<0.05\right) . D, B c l-2$ was not affected by hyperoxia or p53 deficiency.

genes. The truncated, $\mathrm{BH} 3$ domain only, Bcl-2 family members were not studied in the current work, but their function is also less well understood. It is possible, although unlikely, that these other genes play a role in hyperoxia-induced cell death. Our results demonstrate that independent regulation of the $\mathrm{Bcl}-2$ genes in hyperoxia is not distinguished by their effect on apoptosis. Anti-apoptotic Bcl- $X_{L}$ mRNA was increased, whereas Bcl-w and Bfl-1 decreased during oxygen exposure. The mRNA for the pro-apoptotic $\mathrm{Bcl}-\mathrm{X}_{\mathrm{S}}$ gene, encoding domains $\mathrm{BH} 3$ and $\mathrm{BH} 4$, was 


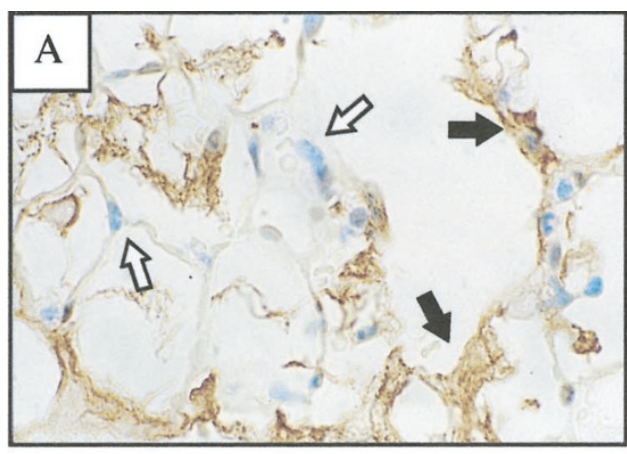

$p 53(+/+)$

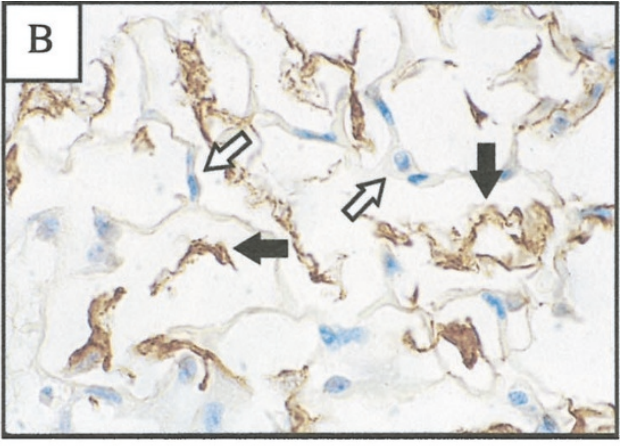

$p 53(-/-)$

Figure 8.

DNA fragmentation in p53-deficient mice. TUNEL staining of $p 53(+/+)(A)$ and $p 53(-/-)(B)$ lungs following 84 hours exposure to hyperoxia. Filled arrow depicts TUNEL-positive debris and cells; open arrow depicts TUNEL-negative cells. Each panel is representative of three animals. Note the abundant TUNEL-positive debris in both $\mathrm{p} 53$ wild-type and deficient lungs.

not detected in these assays. In contrast to $\mathrm{Bcl}-\mathrm{X}_{\mathrm{L}}$ or $\mathrm{Bcl}-\mathrm{w}$, regulation of both $\mathrm{Bax}$ and $\mathrm{Bfl}-1$ mRNAs in response to hyperoxia was p53-dependent. Thus, multiple pathways are involved in the regulation of the $\mathrm{Bcl}-2$ gene family during hyperoxia.

Bax was the only pro-apoptotic member whose expression was increased by hyperoxia, whereas the expression of Bad and Bak was unchanged and $\mathrm{Bcl}-\mathrm{X}_{\mathrm{s}}$ was undetectable. In situ hybridization demonstrated that hyperoxia increased Bax mRNA in a diffuse parenchymal pattern. Unexpectedly, Bax mRNA was increased in cells known to be resistant to hyperoxia-induced death, including the bronchiolar epithelial and alveolar type II cells, suggesting that Bax expression by itself does not dictate whether cells die in hyperoxia. In addition, Western blot analysis, although demonstrating an increase in Bcl- $\mathrm{X}_{\mathrm{L}}$ protein, showed no increase in Bax protein. This could be explained by a decrease in Bax protein in some cells with an increase in others, resulting in no change in overall levels in lung homogenates. However, the in situ hybridization assays do not suggest differential expression of Bax mRNA in specific cell types. Unfortunately, attempts to localize and semiquantify Bax protein by immunohistochemistry in hyperoxiaexposed lung tissue have been unsuccessful to date. The further observation that $p 53$-deficient mice are no more sensitive or resistant to oxygen-induced lung injury, despite the failure to induce Bax or reduce Bfl-1, suggests that neither of these genes plays a significant role in pulmonary oxygen toxicity.

Hyperoxia increased the expression of $\mathrm{Bcl}-\mathrm{X}_{\mathrm{L}}$ mRNA throughout the bronchioles and parenchyma in a manner that overlapped with Bax mRNA expression. The patterns of $\mathrm{Bcl}-\mathrm{X}_{\mathrm{L}}$ and Bax mRNA expression coincide, at least in part, with TUNEL-positive cells, cells likely to have DNA fragmentation. Electron microscopy, however, suggests that these cells are not classically apoptotic. The majority of cells do not have condensed chromatin, reduced cell size, or membrane blebbing, events typical of ACD. Unlike Bax, Bcl- $X_{L}$ protein was increased in lung lysates following oxygen exposure, suggesting that the ratio of $\mathrm{Bcl}-\mathrm{X}_{\mathrm{L}}$ protein to
Bax protein was increased, at least in the lung as a whole. The increased levels of $\mathrm{Bcl}-\mathrm{X}_{\mathrm{L}}$ in bronchiolar and alveolar type II epithelial cells supports the hypothesis that induction of this anti-apoptotic member could be protecting these cells from apoptosis. However, Bcl- $X_{L}$ was expressed uniformly throughout the parenchyma, consistent with expression in microvascular endothelial and type I epithelial cells, which are sensitive to hyperoxia, suggesting the $B c l-X_{L}$ does not protect these cells from death and disruption. It is possible that prolonged exposure to oxygen concentrations greater than $95 \%$ overwhelms the antioxidant capacity of these cells of the lung and has such a toxic effect that they are unable to complete an apoptotic program of cell death, an adenosine triphosphate (ATP), energy-requiring program. Bcl-2 family members, such as $\mathrm{Bcl}-\mathrm{X}_{\mathrm{L}}$ and $\mathrm{Bax}$, may play a role in response to hyperoxia under less severe circumstances.

The relative expression and activity of $\mathrm{Bcl}-2$ members must be tightly regulated to prevent survival of terminally injured cells or the death of healthy cells. One protein that regulates expression of Bcl-2 family members is the p53 tumor suppressor, which accumulates in cells with DNA damage and induces apoptosis by increasing Bax expression (Friedlander et al, 1996). Previous studies have shown that hyperoxia increases p53 in vitro (Shenberger and Dixon, 1999) and in vivo (Barazzone et al, 1998; Buckley et al, 1998; O'Reilly et al, 1998a). The present study now extends these findings by demonstrating that Bax induction and $\mathrm{Bfl}-1$ repression during hyperoxic injury is p53dependent. However, p53-deficiency and, therefore, failure to alter Bax or Bfl-1 did not modify hyperoxic lung injury as assessed by edema (Barazzone et al, 1998), DNA fragmentation (O'Reilly et al, 2000), or a lung injury index (data not shown). Although we observed a slight increase in edema underlying terminal bronchiolar epithelium in hyperoxic p53 (-/-) lungs, there is no further evidence that this altered morbidity and mortality.

In conclusion, we have found that hyperoxia induces complex and overlapping patterns of expres- 
sion for some members of the Bcl-2 gene family and that p53-dependent induction of Bax or repression of $\mathrm{Bfl}-1$ does not modulate lung injury/death in response to severe hyperoxia. Our findings do not demonstrate a definite link between Bcl-2 family member expression and apoptosis in the whole lung exposed to hyperoxia. However, since individual cell types may respond to hyperoxia independently, it is possible that the current methods of study are too insensitive to detect a cell-specific response. Nonetheless, our inability to link Bcl-2 genes with hyperoxia-induced apoptosis is consistent with over 30 years of ultrastructural morphologic studies demonstrating that hyperoxia kills cells primarily by necrosis (Adamson et al, 1970; Crapo et al, 1980). Similarly, in vitro-cultured A549 lung adenocarcinoma cells die by necrosis when exposed to hyperoxia (Kazzaz et al, 1996). It is intriguing to consider that cells may be attempting to undergo programmed cell death that cannot be completed because of ATP depletion and/or overall oxidization of essential molecules. In addition, because an orderly balance of apoptosis and proliferation are likely to occur during recovery in room air, it remains to be determined whether p53 and $\mathrm{Bcl}-2$ proteins are essential for normal repair of the oxygeninjured lung. These questions can be answered as the reagents and models for their study are developed.

\section{Materials and Methods}

\section{Animals and Exposures}

Adult 8-week-old male C57BL/6J mice were obtained from Jackson Laboratories (Bar Harbor, Maine). C57BL/129J hybrid p53 wild-type $(+/+)$ and null (-/-) mice were obtained from Taconic (Germantown, New York). All mice were housed under pathogen-free conditions for 1 week before experimental exposure. Mice were exposed to room air (controls) or to greater than $95 \%$ oxygen by placing the cages inside a Plexiglas chamber of approximately $32 \times 14 \times 24$ inches as described (O'Reilly et al, 1998a, 1998b). Oxygen concentrations were monitored each day with a miniOXI analyzer from Catalyst Research Corporation (Owings Mills, Maryland). Animals were permitted food and water ad libitum and were killed with intraperitoneal injection of pentobarbital $(65 \mathrm{mg} / \mathrm{kg}$ ) after 48 to 88 hours. Approximately $50 \%$ of the mice had severe respiratory distress by the latter time. All protocols were reviewed and approved by the University of Rochester's University Committee on Animal Resources.

\section{Tissue}

Control and hyperoxic lungs were harvested and analyzed for RNA and histology. At least three mice were used for each analysis. The lungs were exposed, the left lobes were ligated and removed for isolation of RNA, and the right lobes were inflation-fixed for histology through the trachea with $100 \mathrm{~mm}$ cacodylic acid, $\mathrm{pH} 7.4$, with $2 \%$ glutaraldehyde at $10 \mathrm{~cm}$ of water pressure for 15 minutes. Lungs were dehy- drated through graded alcohol and embedded in paraffin, and $5-\mu \mathrm{m}$ sections prepared. Some lungs were fixed in $2 \%$ glutaraldehyde, embedded in plastic, and stained with osmium tetroxide for ultrastructural studies with the assistance of the Electron Microscopy Core Facility at the University of Rochester, Rochester, New York.

\section{RNA Extraction and Analysis}

Lungs were homogenized in $4 \mathrm{M}$ guanidine isothiocyanate, $0.5 \% \mathrm{~N}$-laurylsarcosine, $20 \mathrm{~mm}$ sodium citrate, and $0.1 \mathrm{M} \beta$-mercaptoethanol using a Techmar homogenizer (Techmar Company, Cincinnati, Ohio). RNA was extracted using acid phenol and phase lock columns (5 Prime-3 Prime, Boulder, Colorado) and resuspended in diethylpyrocarbonate-treated water. The amount of RNA in an aqueous solution was determined by absorbance at $260 \mathrm{~nm}$. RNA was electrophoretically separated on $1.2 \%$ agaroseformaldehyde gel and transferred to Nytran (Sleicher \& Schull, Keene, New Hampshire). Blots were prehybridized and then hybridized at $65^{\circ} \mathrm{C}$ in $1 \%$ bovine serum albumin (BSA), 7\% sodium dodecylsulfate, $0.5 \mathrm{M}$ sodium phosphate, and $1 \mathrm{~mm}$ EDTA. Radioactive cDNA probes were prepared by random primer labeling (Gibco/BRL, Grand Island, New York) using [ $\left.{ }^{32} \mathrm{P}\right]-$ dCTP (3000 Ci/mmole; New England Nuclear Research Products, Boston, Massachusetts). Hybridized blots were washed briefly in $0.1 \%$ BSA, $40 \mathrm{~mm}$ sodium phosphate, and $1 \mathrm{~mm}$ EDTA twice at room temperature before stringent washing in the same buffer at $65^{\circ} \mathrm{C}$. Washed blots were exposed to Kodak X-OMAT AR film, and differences in loading samples were normalized to the mRNA expression of ribosomal protein L32 as described (O'Reilly et al, 1998a, 1998b).

Bax and Bcl- $X_{L}$ cDNAs were obtained by RT-PCR using as templates RNA from the lungs of mice exposed to hyperoxia. Primers containing the translation initiation and termination codons of the target genes with restriction enzyme sites were used to amplify products that were cloned into the BlueScript vector (Stratagene, La Jolla, California). Primer sequences specific for Bax were 5'-ATGTCTCAGAGCAACCGGGAG-3' and 5'-CTTCCGACTGAAGAGTGAGCC-3'. Primer sequences specific for $B c l-X_{L}$ were 5'-ATGGACGGGTCCGGGGAGCAG-3' and 5'-TCAGCCCATCTTCTTCCAGATG-3'. CDNA templates were synthesized at $42^{\circ} \mathrm{C}$ for 30 minutes using reverse transcriptase and $0.5 \mu \mathrm{g}$ of RNA with random primers (Perkin-Elmer, Foster City, California). Products were amplified using $15 \mu \mathrm{M}$ of primers and cycling 35 times at $94^{\circ} \mathrm{C}$ for 30 seconds, $55^{\circ} \mathrm{C}$ for 30 seconds, and $72^{\circ} \mathrm{C}$ for one minute. The DNA was extracted with phenol and chloroform before precipitating with ethanol. Resulting cDNAs were cloned into BlueScript vectors using unique restriction enzyme sites added to the $5^{\prime}$-end of the primers (not shown in primers). Cloned products were sequenced and aligned to their respective genes using MacVector sequence analysis software to confirm their identity (Kodak, Rochester, New York). 
RNase protection assays were performed with the murine Apo-2 riboprobe template kit (Pharmigen, San Diego, California). Riboprobe synthesis reaction contained $50 \mathrm{ng}$ of template set, $100 \mu \mathrm{Ci}\left[{ }^{32} \mathrm{P}\right]$ UTP $(3,000$ $\mathrm{Ci} / \mathrm{mmol}$; Dupont NEN, Wilmington, Delaware), 137.5 nmol each of ATP, GTP, and CTP, 3.05 pmol UTP, 100 nmol dithiothreitol, $40 \mathrm{U}$ Rnasin, and $20 \mathrm{U}$ T7 RNA polymerase (Pharmigen) in $1 \times$ transcription buffer (40 $\mathrm{mm}$ Tris- $\mathrm{HCl}, \mathrm{pH} 7.5,6 \mathrm{~mm} \mathrm{MgCl}_{2}$ ). The reaction was incubated for 60 minutes at room temperature followed by an additional 30 minutes at $37^{\circ} \mathrm{C}$ in the presence of $2 \mathrm{U}$ RNase-free DNase. Riboprobes were extracted with phenol/chloroform and precipitated with ethanol and ammonium acetate. Probes were resuspended in $50 \mu \mathrm{l}$ hybridization buffer $(400 \mathrm{~mm}$ $\mathrm{NaCl}, 40$ mм PIPES, pH 6.7, 1 mм EDTA, pH 8.0, and $80 \%$ formamide) and diluted to $2.4 \times 10^{5} \mathrm{cpm} / \mu \mathrm{l}$ before incubating with $5 \mu \mathrm{g}$ denatured total RNA at $56^{\circ} \mathrm{C}$ for 16 hours. Hybridized probes were digested by the addition of $100 \mu \mathrm{l}$ RNase buffer $(0.192 \mu \mathrm{g} / \mathrm{ml}$ RNase A, $600 \mathrm{U} / \mathrm{ml}$ RNase T1, $10 \mathrm{~mm}$ Tris- $\mathrm{HCl}, \mathrm{pH} 7.5$, $300 \mathrm{~mm} \mathrm{NaCl}, 5 \mathrm{~mm}$ EDTA, pH 8.0) for 45 minutes at $30^{\circ} \mathrm{C}$. Samples were incubated with proteinase $\mathrm{K}$, yeast tRNA, and SDS before extracting with phenol/ chloroform and precipitating with ethanol. Protected products were separated on a $6 \%$ acrylamide/8 M urea sequencing gel, dried, and visualized by exposure on Phosphorlmager screens. The intensity of each product was measured and quantified with ImageQuant software (Molecular Dynamics, Sunnyvale, California).

\section{In Situ Hybridization}

Radio-labeled sense and anti-sense probes were synthesized using T3 and T7 promoters with $\left[{ }^{33} \mathrm{P}\right]$ to a specific activity of $3.3 \times 10^{9} \mathrm{dpm} / \mu \mathrm{g}$ and digested to a length of approximately 200 bp by alkaline hydrolysis. Sections were hybridized for 16 hours at $55^{\circ} \mathrm{C}$ and washed and digested with RNase A as described (Maniscalco et al, 1995; O'Reilly et al, 1998b). The slides were washed stringently at $65^{\circ} \mathrm{C}$ in $0.1 \times$ SSC for 30 minutes, dipped in a 1:1 dilution of NTB-2 emulsion (Kodak), and exposed at $4^{\circ} \mathrm{C}$ for 2 weeks before developing and counterstaining with hematoxylin and eosin.

\section{DNA Fragmentation and Lung Injury}

Terminal transferase dUTP nick end-labeling (TUNEL) staining was performed using an ApopTag kit (Intergen Co, Purchase, New York) as previously described (O'Reilly et al, 1998a). This assay uses the enzyme terminal transferase to add digoxigenin-conjugated nucleotides to free 3'-hydroxyl groups on DNA. Horseradish peroxidase-conjugated anti-digoxigenin antibodies are then applied and visualized as a brown precipitate by reaction with 3,3 '-diaminobenzidine (DAB). TUNEL-positive nuclei are visualized in contrast to TUNEL-negative nuclei that stain blue by reaction with methyl green. Staining specificity was confirmed by the lack of TUNEL-positive DAB precip- itate when terminal transferase was omitted from the reactions. Lung injury was assessed, in coded sections stained with hematoxylin and eosin, by a veterinary pathologist. The parameters examined were the degree of proteinaceous fluid, inflammatory infiltrates, and cell death observed in both the bronchioles and parenchyma. Sections from lungs of mice exposed to room air were included as an internal standard.

Genomic DNA was isolated from lungs that were frozen in liquid nitrogen and crushed with a mortar and pestle. The DNA was purified using a TACS apoptotic DNA laddering kit and separated in 1.5\% Trevigel as described by the manufacturer (Trevigen, Inc., Gaithersburg, Maryland). The gels were digitally imaged and enhanced following staining with SYBR Green I, which has a higher affinity for DNA and a greater fluorescence upon binding than does ethidium bromide (Molecular Probes, Eugene, Oregon). In addition, the affinity of the dye for the modified agarose was low, allowing for visualization of faint bands.

\section{Statistical Analyses}

Values are expressed as mean \pm SD Group means were compared by ANOVA with Fisher's PLSD post hoc analysis using StatView software (SAS Institute, Cary, North Carolina) for Macintosh. $p<0.05$ was considered to be significant.

\section{Acknowledgements}

We thank Erik Thingvoll for confirming the genotype of p53-deficient mice and Karen de Mesy Jensen for electron microscopy.

\section{References}

Adams JM and Cory S (1998). The Bcl-2 protein family: Arbiters of cell survival. Science 281:1322-1326.

Adamson IY, Bowden DH, and Wyatt JP (1970). Oxygen poisoning in mice. Ultrastructural and surfactant studies during exposure and recovery. Arch Pathol 90:463-472.

Ansari B, Coates PJ, Greenstein BD, and Hall PA (1993). In situ end-labelling detects DNA strand breaks in apoptosis and other physiological and pathological states. J Pathol 170:1-8.

Barazzone C, Horowitz S, Donati YR, Rodriguez I, and Piguet PF (1998). Oxygen toxicity in mouse lung: Pathways to cell death. Am J Respir Cell Mol Biol 19:573-581.

Buckley S, Barsky L, Driscoll B, Weinberg K, Anderson KD, and Warburton D (1998). Apoptosis and DNA damage in type 2 alveolar epithelial cells cultured from hyperoxic rats. Am J Physiol 274:L714-L720.

Cory S (1998). Cell death throes. Proc Natl Acad Sci USA 95:12077-12079.

Crapo JD (1986). Morphologic changes in pulmonary oxygen toxicity. Annu Rev Physiol 48:721-731.

Crapo JD, Barry BE, Foscue HA, and Shelburne J (1980). Structural and biochemical changes in rat lungs occurring during exposures to lethal and adaptive doses of oxygen. Am Rev Respir Dis 122:123-143. 
Enari M, Sakahira H, Yokoyama H, Okawa K, Iwamatsu A, and Nagata S (1998). A caspase-activated DNase that degrades DNA during apoptosis, and its inhibitor ICAD. Nature 391:43-50.

Friedlander P, Haupt Y, Prives C, and Oren M (1996). A mutant p53 that discriminates between p53-responsive genes cannot induce apoptosis. Mol Cell Biol 16:4961-4971.

Grasl-Kraupp B, Ruttkay-Nedecky B, Koudelka H, Bukowska K, Bursch W, and Schulte-Hermann R (1995). In situ detection of fragmented DNA (TUNEL assay) fails to discriminate among apoptosis, necrosis, and autolytic cell death: A cautionary note. Hepatology 21:1465-1468.

Johnston CJ, Stripp BR, Piedbeouf B, Wright TW, Mango GW, Reed CK, and Finkelstein JN (1998). Inflammatory and epithelial responses in mouse strains that differ in sensitivity to hyperoxic injury. Exp Lung Res 24:189-202.

Kazzaz JA, Xu J, Palaia TA, Mantell L, Fein AM, and Horowitz $S$ (1996). Cellular oxygen toxicity. Oxidant injury without apoptosis. J Biol Chem 271:15182-15186.

Kerr JF, Wyllie AH, and Currie AR (1972). Apoptosis: A basic biological phenomenon with wide-ranging implications in tissue kinetics. Br J Cancer 26:239-257.

Liu X, Li P, Widlak P, Zou H, Luo X, Garrard WT, and Wang X (1998). The 40-kDa subunit of DNA fragmentation factor induces DNA fragmentation and chromatin condensation during apoptosis. Proc Natl Acad Sci USA 95:8461-8466.

Maniscalco WM, Watkins RH, Finkelstein JN, and Campbell $\mathrm{MH}$ (1995). Vascular endothelial growth factor mRNA increases in alveolar epithelial cells during recovery from oxygen injury. Am J Respir Cell Mol Biol 13:377-386.

O’Reilly MA, Staversky RJ, Flanders KC, Johnston CJ, and Finkelstein JN (1997). Temporal changes in expression of TGF-beta isoforms in mouse lung exposed to oxygen. Am J Physiol 272: L60-L67.

O'Reilly MA, Staversky RJ, Stripp BR, and Finkelstein JN (1998a). Exposure to hyperoxia induces p53 expression in mouse lung epithelium. Am J Respir Cell Mol Biol 18: 43-50.
O'Reilly MA, Staversky RJ, Watkins RH, and Maniscalco WM (1998b). Accumulation of p21(Cip1/WAF1) during hyperoxic lung injury in mice. Am J Respir Cell Mol Biol 19:777-785.

O'Reilly MA, Staversky RJ, Watkins RH, Maniscalco WM, and Keng PC (2000). p53-independent induction of GADD45 and GADD153 in mouse lungs exposed to hyperoxia. Am J Physiol Lung Cell Mol Physiol 278:L552-L559.

Oltvai ZN, Milliman CL, and Korsmeyer SJ (1993). Bcl-2 heterodimerizes in vivo with a conserved homolog, Bax, that accelerates programmed cell death. Cell 74:609-619.

Raffray M and Cohen GM (1997). Apoptosis and necrosis in toxicology: A continuum or distinct modes of cell death? Pharmacol Ther 75:153-177.

Shenberger JS and Dixon PS (1999). Oxygen induces S-phase growth arrest and increases p53 and p21(WAF1/ CIP1) expression in human bronchial smooth-muscle cells. Am J Respir Cell Mol Biol 21:395-402.

Thornberry NA and Lazebnik Y (1998). Caspases: Enemies within. Science 281:1312-1316.

Tsujimoto Y, Finger LR, Yunis J, Nowell PC, and Croce CM (1984). Cloning of the chromosome breakpoint of neoplastic $B$ cells with the $t(14 ; 18)$ chromosome translocation. Science 226:1097-1099.

Waxman $A B$, Einarsson $O$, Seres $T$, Knickelbein RG, Warshaw JB, Johnston R, Homer RJ, and Elias JA (1998). Targeted lung expression of interleukin-11 enhances murine tolerance of $100 \%$ oxygen and diminishes hyperoxiainduced DNA fragmentation. J Clin Invest 101:1970-1982.

Wikenheiser KA, Wert SE, Wispe JR, Stahlman M, D'AmoreBruno M, Singh G, Katyal SL, and Whitsett JA (1992). Distinct effects of oxygen on surfactant protein $B$ expression in bronchiolar and alveolar epithelium. Am J Physiol 262: L32L39.

Yin XM, Oltvai ZN, and Korsmeyer SJ (1994). BH1 and BH2 domains of $\mathrm{Bcl}-2$ are required for inhibition of apoptosis and heterodimerization with Bax. Nature 369: 321-323. 